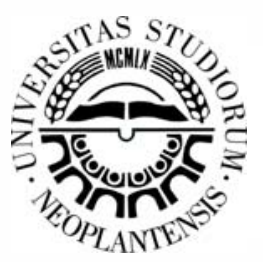

\title{
Influence of HVOF deposition thickness on adhesion strength of WC-CrC-Ni coatings
}

\author{
Alin Constantin Murariu, Ion Aurel Perianu
}

National R\&D Institute of Welding and Material Testing - ISIM Timisoara, 30 Mihai Viteazul Blv.,300222, Timisoara, Romania

\section{ABSTRACT}

In this paper, adhesion strength of WC-CrC-Ni coatings obtained by HVOF thermal spraying process of WOKA7504 powder has been studied in correlation with deposition thickness, chemical and structural properties. Besides the parameters strictly related to the process, deposition thickness was found to be the most significant factor affecting the adhesion strength. In the frame of experimental program 304L stainless steel and S235JR structural steel were used as substrate. Mechanical tests, SEM and EDX analysis, have been performed in order to assess structural and mechanical properties, phase composition of the deposited layers. Maximum average adhesion strength has been experimentally found of $23.4 \mathrm{~N} / \mathrm{mm}^{2}$ for stainless steel and of $35.8 \mathrm{~N} / \mathrm{mm}^{2}$ for structural steel, for a deposition thickness of $220 \mu \mathrm{m}$, achieved in two layers. Once the coatings' thickness increases, the adhesion strength decreases constantly and over thickness of 400 to 650 $\mu \mathrm{m}$, the existing coating imperfections and elongated carbides placed in the interlayer interface area could fail due to the thermal stresses during the HVOF thermal spraying process, since they are brittle stress concentrators and thus leading tocracking of coatings at small loads, since the coating layershave high hardness of 990 to $1151 \mathrm{HV} 1$.

Key words: protective coatings, tungsten carbide, HVOF, adhesive strength, failure mechanism

\section{INTRODUCTION}

This Currently thermal-sprayed coatings are largely used to increase the lifespan and service performance of components. Other applications include component repairing and fabrication of net-shape components [1] and general fabrication of components protected by wear resistant layers [2]-[7], by erosion - corrosion resistant layers in aggressive environments [8]-[12] or by layers used as thermal barrier [13]-[16].

High Velocity Oxygen Fuel (HVOF), thermal spraying [17] has been a very successful process in the spraying of wear resistant coatings due to superior adhesion strengths, higher density and less decarburization, relative to many other thermal spraying processes. The $\mathrm{WC}-\mathrm{CrC}-\mathrm{Ni}$ coating layers, achieved by the HVOF process, have very high hardness and good corrosion resistance and thus can be used to protect different components (e.g. pipes, elbows, vane pumps, cylinders, valves, mining equipment etc.) and are used in various industries, as an alternative to hard chrome plating. The process parameters used to obtain the coating have a major effect on the maximum temperature of components, reached during the process, resulting in a significant difference in the microstructural properties [18]-[20] and mechanical behaviour of the coatings [21], [22], residual stress after deposition [23], which affect the component performance.

Study on tribological and corrosion behaviour [24], [25], and on grinding effects on the adhesion strength [26] of HVOF thermally sprayed WC composite has been done before, but the potential of this type of coatings has not yet been exhausted. Due to the complexity of the process (large number of technological parameters, e.g.: spraying distance, spraying gun travel speed, oxygen-fuel ratio and deposition temperature, type and flow ratio of powder, particle size distribution and its production method, chemical composition of the metallic binder, mechanical properties of substrate, including surface roughness and oxidation state, post-treatment etc.), [27]-[29], more intensive studies are required for process optimisation, [30] and to define correlations between process parameters, coating composition and the microstructure obtained [31], [32], physical and mechanical properties of coatings, including bonding interface properties [33], coating thickness and the achieved coating adherence strength. Different qualitative or quantitative methods

* Corresponding author's.e-mail: alin@isim.ro 
allow assessing the adhesion strength of thermally sprayed coatings [34]-[36], e.g. scratching test, tensile test, shear test, LASer adhesion test, bulge and blister test, interfacial indentation test and three-point bend test. In this paper, the influence of deposition thickness on adhesion strength of $\mathrm{WC}-\mathrm{CrC}-\mathrm{Ni}$ coatings obtained by the HVOF thermal spraying process was investigated. The EN 582 standard [37] was used to perform the adhesion tests.

\section{EXPERIMENTAL WORK}

\subsection{Material and methods}

The tests were performed on S235JR carbon steel and 304L stainless steel blocks used as substrate, protected by WC-CrC-Ni coating layers obtained by HVOF process using WOKA 7504 powder. The chemical composition and the mechanical properties of the substrates are presented in table 1 and table 2 , respectively. The chemical composition and characteristics of the powder are presented in table 3 and table 4, respectively. The method used to assess the adhesion strength of $\mathrm{WC}-\mathrm{CrC}-$ Ni coatings was according to the EN 582 standard [37].

Table 1. Chemical composition [\%] of substrate materials [38], [39].

\begin{tabular}{|c|c|c|c|c|c|c|c|c|c|}
\hline Steel & $\begin{array}{c}\mathrm{C} \\
\max \end{array}$ & $\mathrm{Cr}$ & $\mathrm{Ni}$ & $\begin{array}{c}\mathrm{Si} \\
\mathrm{max}\end{array}$ & $\begin{array}{c}\mathrm{Mn} \\
\max .\end{array}$ & $\begin{array}{c}\mathrm{P} \\
\max .\end{array}$ & $\begin{array}{c}\mathrm{S} \\
\max \end{array}$ & $\begin{array}{c}\mathrm{N} \\
\max .\end{array}$ & $\begin{array}{c}\mathrm{Cu} \\
\max .\end{array}$ \\
\hline $\begin{array}{c}304 \mathrm{~L} \\
(1.4307)\end{array}$ & 0.03 & $\begin{array}{r}18.0 \\
20.0\end{array}$ & $\begin{array}{r}8.0 \\
12.0\end{array}$ & 1.0 & 2.0 & 0.045 & 0.03 & - & - \\
\hline $\begin{array}{c}\text { S235JR } \\
(1.0038)\end{array}$ & 0.19 & - & - & - & 1.5 & 0.045 & 0.04 & 0.01 & 0.60 \\
\hline
\end{tabular}

Table 2. Mechanical properties of substrate materials [38], [39]

\begin{tabular}{|c|c|c|c|}
\hline Steel & $\begin{array}{c}\mathrm{Rm}_{2} \\
{\left[\mathrm{~N} / \mathrm{mm}^{2}\right]}\end{array}$ & $\begin{array}{c}\mathrm{Rp} 0.2 \\
{[\mathrm{~N} / \mathrm{mm} 2]}\end{array}$ & $\mathrm{A}_{\min }[\%]$ \\
\hline 304L (1.4307) & $\mathrm{min} .515$ & $\mathrm{~min} .205$ & 4 \\
\hline S235JR (1.0038) & $360-510$ & min. 225 & 2 \\
\hline
\end{tabular}

Table 3. Chemical composition [\%] of the powder WOKA 7504, manufacturer's data [40]

\begin{tabular}{|c|c|c|c|c|c|c|}
\hline Powder & $\mathrm{Cr}$ & $\mathrm{Ni}$ & $\mathrm{Co}$ & $\mathrm{C}$ & $\mathrm{Fe}$ & $\mathrm{W}$ \\
\hline WOKA & $38.5-$ & $10.0-$ & $2.9-$ & $7.7-$ & $<0.5$ & \multirow{2}{*}{ the rest } \\
7504 & 43.5 & 13.0 & 4.1 & 8.5 & & \\
\hline
\end{tabular}

Table 4. Characteristics of the powder WOKA 7504, manufacturer's data [40]

\begin{tabular}{|l|l|}
\hline Classification & Cr and W carbides \\
\hline Chemical composition & Cr3C2 37WC 18Metal Alloy \\
\hline Manufacturing method & Agglomeration and sintering \\
\hline Morphology & Spheroidal \\
\hline Dimensions & 10 to $30 \mu \mathrm{m}$ \\
\hline The aspect & Rough \\
\hline Apparent density & $3.1-3.8 \mathrm{~g} / \mathrm{cm}^{3}$ \\
\hline Operating temperature & $<700^{\circ} \mathrm{C}$ \\
\hline Role & Corrosion and wear resistant \\
\hline Recommended process & HVOF \\
\hline
\end{tabular}

\subsection{Sample preparation and experimental setup}

In order to perform the tests, special samples with a diameter of $25 \mathrm{~mm}$ were made of S235JR and 304L steel, according to the above-mentioned test standard. The sample consists of two identical cylindrical blocks. On the front surface of each block, a protective coating layer of WC-CrC-Ni was deposited by HVOF thermal spraying process. Before performing the hard layers' deposition, both types of materials used as substrate have undergone a process of preparation by degreasing (with alcohol) and sandblasting of surfaces (with $\mathrm{Al}_{2} \mathrm{O}_{3}$ particles size $\mathrm{F} 20$ of $850-1180 \mu \mathrm{m}$, having high hardness and rugged shapes), mandatory procedure to be done in order to obtain proper quality surfaces for high performance coatings. This procedure isuse not only for rust removal to get a virgin surface, but also to provide a compressive stress on the substrate surface and to generate anchor pattern texture, which results in appropriate mechanical bond characteristics of the coating to the substrate. Thermal spraying of coating was performed right after completion of the surfaces preparation in order to avoid forming of a thick oxide layer on the components' surfaces, which could affect the deposition quality. In order to obtain coatings with controlled thickness, an experimental setup has been designed, consisting of specialized HVOF (High Velocity Oxygen Fuel) thermal spraying equipment, which has a control module, a spraying gun mounted on a robotic arm and a powder feeder. Since the layer thickness depends on many parameters of the deposition process, during experiments some of process parameters remained constant: air flow $200 \mathrm{l} / \mathrm{min}$, oxygen flow 185 $1 / \mathrm{min}$, propane flow $68 \mathrm{l} / \mathrm{min}$, spraying gun - piece offset $225 \mathrm{~mm}$, the powder flow $60 \mathrm{~g} / \mathrm{min}$, the spraying gun travel speed $75 \mathrm{~mm} / \mathrm{s}$ and the step between two successive passes was calculated, based on the deposited material distribution by spraying in the given conditions.

Based on the distribution shown in Fig. 1, the step between two successive passes was graphically determined, Fig. 2, in order to obtain a coating thickness as uniform as possible, Fig.3 (for one pass) and Fig. 4 (for two passes).

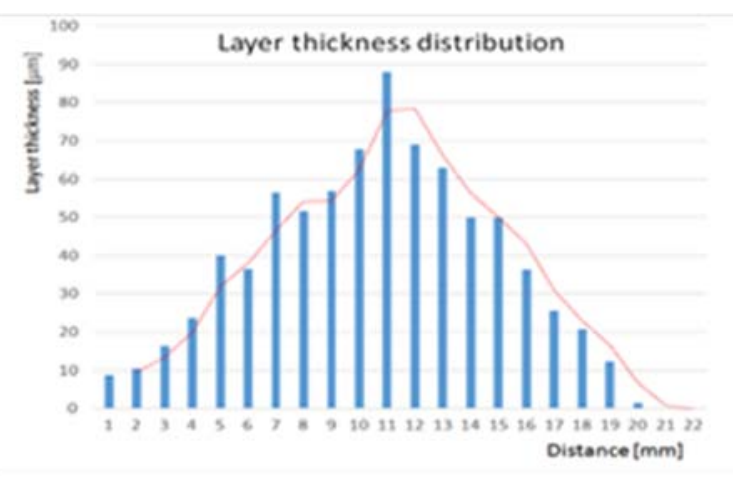

Fig. 1 Layer thickness distribution per pass

Thus, for the parameters above specified, the step used was $\mathrm{p}=9 \mathrm{~mm}$. Although the jet of sprayed particles comes into contact with the metal substrate for a very short time (value that varies depending on the parameters of HVOF thermal spraying process), however, the absorbed heat is accumulated in the substrate and, in the case of small components, it can reach very high values, 
leading to component degradation or affecting the deposition quality. For monitoring the sample temperature during the HVOF process, an infrared camera FLIR System A40 and a dedicated software for recording of thermographic imaging were used.

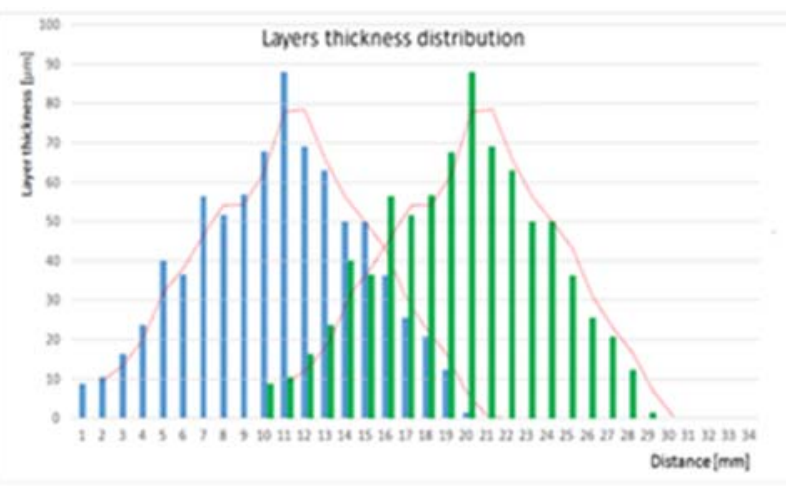

Fig. 2 Determining the distance between two passes

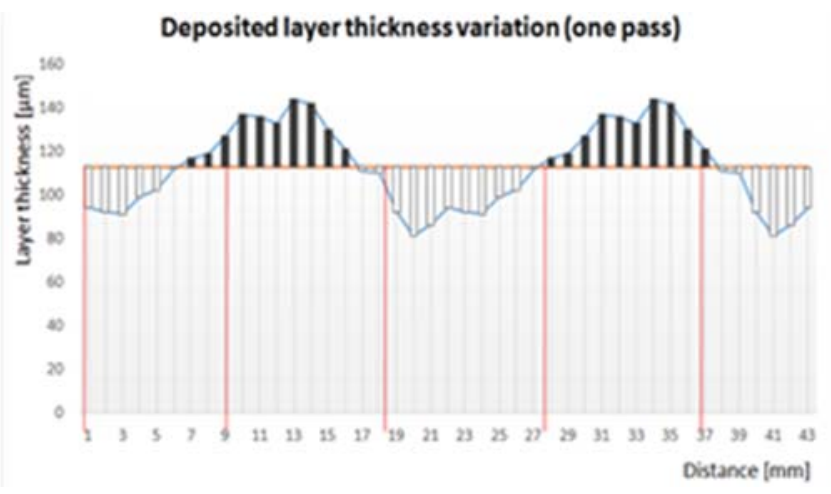

Fig 3. Layer thickness - one pass

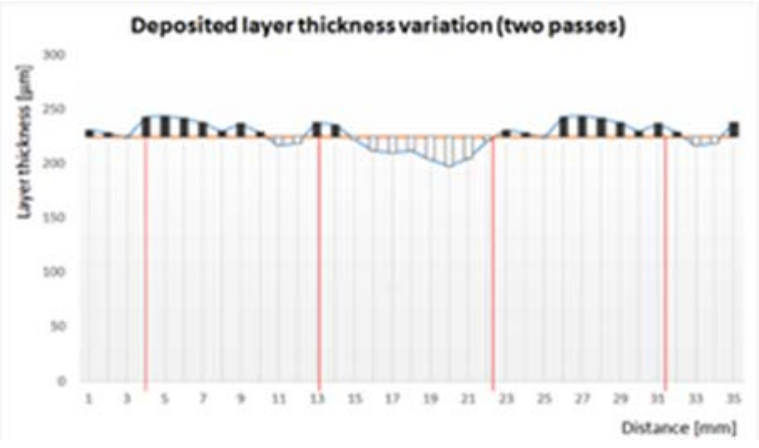

Fig. 4. Layer thickness - two passes

In order to assess the temperature distribution of the samples surfaces during the HVOF thermal spraying process, a plate of $200 \times 200 \mathrm{~mm}$ was used as support and 12 passes were deposited on it. The same parameters were used as in the case of cylindrical blocks. Temperatures were recorded and the variation of the sample's surface temperature, during $\mathrm{HVOF}$ thermal spraying process, is presented in Fig. 5.

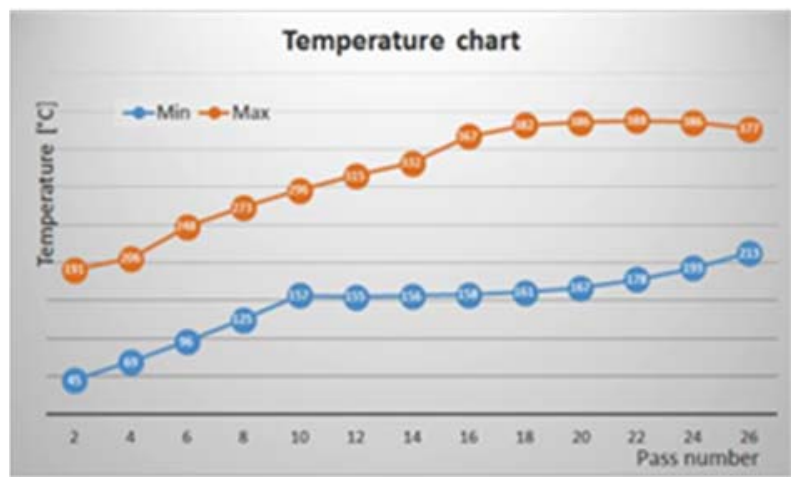

Fig. 5. Variation of the sample's surface temperature during HVOF process

It has been found that during the spraying process the sample temperature increases according to the number of passes and the number of layers deposited. Thus, although after completion of the first deposited layer (after 12 passes), $36 \%$ of the sample surface has a temperature of 291 to $325{ }^{\circ} \mathrm{C}$ and $64 \%$ of the sample surface has a temperature below $290{ }^{\circ} \mathrm{C}$, in case of continuously deposition of two layers, at the end of the second layer, $25 \%$ of the sample surface has a temperature of 361 to $388{ }^{\circ} \mathrm{C}$ and only $14 \%$ of the sample surface has a temperature below $290{ }^{\circ} \mathrm{C}$. After completion of the successive deposition layers, the cylindrical blocks are bound together using a high strength adhesive, so that the coated front faces come into contact. After making the adhesive bond, and waiting to solidify ( 24 hours), the obtained sample is mounted in the testing machine and tested for tensile strength. The loading rate was $1 \mathrm{~mm} / \mathrm{min}$ and tests were made on three samples for each coating thickness, according to the number of layers deposited. The experimental program consists of two, four and six successive deposition layers on the two types of metal substrate, using HVOF thermal spraying process of WOKA 7504 powder. For each number of layers and each metal substrate, three samples were prepared and tested. Additionally, in order to assess the adhesive strength, three samples without deposited layers were prepared and tested. The testing equipment used was a tensile testing machine, EDZ 40 type, upgraded using Zwick / Roell technology, with a maximum load of $400 \mathrm{kN}$, equipped with grips and special devices for this type of test. Samples are clamped by the jaws of the tensile testing machine by means of threaded rods on semi-spherical recesses, so as to ensure sample centring and gripping without inducing lateral forces.

Micro hardness measurements were performed on the crosssection of the coatings using a Zwick 3212 equipment and a load of $1000 \mathrm{~g}$ for $10 \mathrm{~s}$. SEM and EDX analyses were done with a Quanta FEG 250 Microscope, produced by FEI, equipped with an EDAX analyser and backscatter electron detectors that allowed to perform scanning electron microscopy analyses in BSD mode. 


\section{RESULTS ANDDISCUSSION}

From thickness measurements of deposited layers conducted in the experimental program, it appears that using the HVOF process parameters presented in section 2.2, a compact deposited layer (Fig. 6) with only few small pores, a good penetration of the coating into the substrate and a thickness about of 100 to $115 \mu \mathrm{m}$ can be achieved.

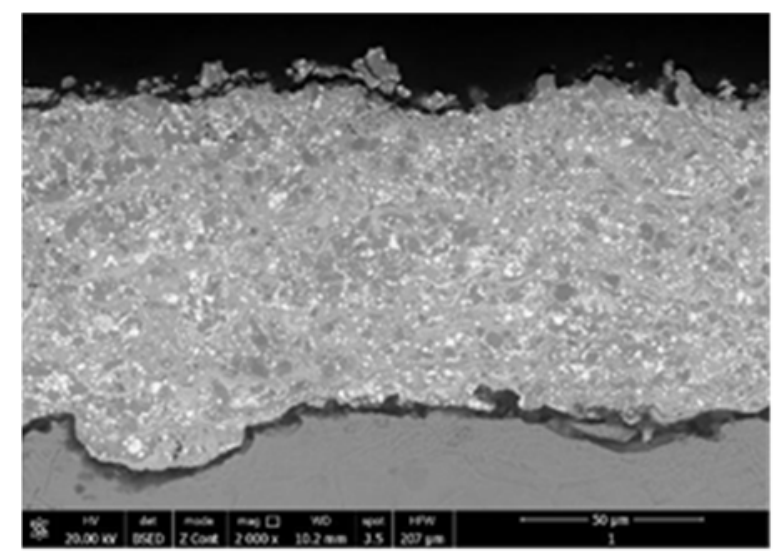

Fig. 6. The SEM microscopic aspect in cross-section of a sample with one deposited layer achieved by HVOF thermal spraying process of WOKA 7504 powder

The differences in the substrate roughness and deposited layers does not significantly influence the amount of metal deposited, thus the layer average thickness has a linear variation with the number of layers deposited, as is presented in Fig. 7.

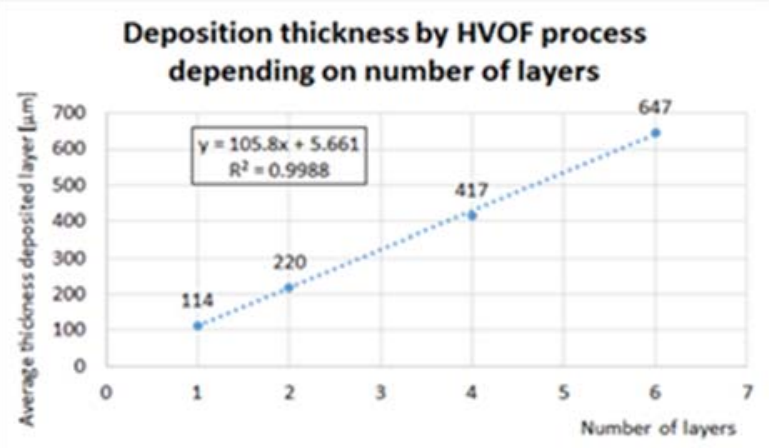

Fig. 7. Deposition thicknesses versus number of layers deposited by HVOF thermal spray process

In correlation with the deposition thickness, table 5 presents the results of the hardness tests on $\mathrm{WC}-\mathrm{CrC}-\mathrm{Ni}$ coatings. Are shown that the average hardness is high comparatively with the substrate (148 to $216 \mathrm{HV} 1$ ) and slightly increases with the number of coating layers, except thick deposits of 6 layers where imperfections affect the hardness tests results as well.

Table 5. HVOF WC-CrC-Ni coatings - Hardness test results, HV 1, average values

\begin{tabular}{|c|c|c|c|}
\hline 1 layer & 2 layers & 4 layers & 6 layers \\
\hline 1003 & 1099 & 1151 & 990 \\
\hline
\end{tabular}

Table 6. Adhesion strength of WC-CrC-Ni coatings obtained by HVOF process, $\mathrm{RH}$ [N/mm2], average values

\begin{tabular}{|c|c|c|c|}
\hline RH [N/mm $\left.{ }^{2}\right]$ & 2 layers & 4 layers & 6 layers \\
\hline $304 \mathrm{~L}(1.4307)$ & 23.4 & 11.7 & 8.0 \\
\hline $\begin{array}{c}\text { S235JR } \\
(1.0038)\end{array}$ & 35.8 & 19.7 & 16.0 \\
\hline $\begin{array}{c}\text { Epoxy Adhesive } \\
\text { (BISON Metal) }\end{array}$ & 37.5 \\
\hline
\end{tabular}

Table 6 presents the average value of adhesion strength of $\mathrm{WC}-\mathrm{CrC}-\mathrm{Ni}$ coatings obtained by HVOF process for two metal substrates. It was revealed that the adhesion strength varies depending on the metal substrate and with the number of layers deposited and thus on the total deposition thickness. To explain these variations, the values obtained for adhesion strength should be correlated with the macroscopic features of the samples' fracture surfaces revealed after performing the tests. Figure 8 presents the aspects of the fracture surface, resulting after the adhesion tests of sample with 2 coating layers, obtained by HVOF deposition of WOKA 7504 powder on S235JR substrate (Fig. 8a) and on 304L substrate (Fig. $8 b)$.
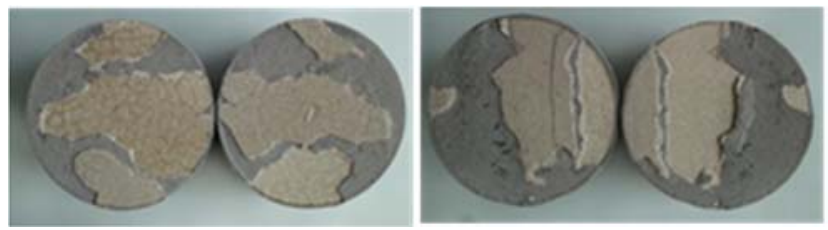

Fig.8. The aspect of samples fracture surfaces, with 2 deposited layers achieved by HVOF thermal spraying process of WOKA 7504 powder, after performing adhesion tests: a) $25 \mathrm{~mm}$ sample, S235JR substrate; b) $25 \mathrm{~mm}$ sample, $304 \mathrm{~L}$ substrate

In both cases, the separation surfaces show a mixed fracture aspect. Failures occurred as well as on adhesive (dark grey) and on the interface between the deposited layers and the substrate. Macroscopically no cracks or tears between layers were detected. This aspect, together with the average value of adhesion strength of 35.8 $\mathrm{N} / \mathrm{mm}^{2}$ recorded in the case of S235JR substrate and of $23.4 \mathrm{~N} / \mathrm{mm}^{2}$ for $304 \mathrm{~L}$ substrate, points out that both the adhesion of deposited layer of the two metal substrates and adhesion between the deposited layers are very good (closest to the adhesion strength of $37.5 \mathrm{~N} / \mathrm{mm}^{2}$ of the adhesive used in the process of samples preparation). The differences between the values of adhesion strength coming from the higher percentage of failure at the layersubstrate level for approx. $40 \%$ of total fracture surface in the case of $304 \mathrm{~L}$ substrate, and less than $25 \%$ of total fracture surface for S235JR substrate.

Figure 9 presents the microscopic aspect of a sample with two deposited layer achieved by HVOF thermal spraying process of WOKA 7504 powder in the areas where the EDX analyses were made. Microstructural analysis reveal that $\mathrm{W}$ and $\mathrm{Cr}$ carbides are evenly distributed in the matrix and small amount of oxides are present, which shows that the process parameters were appropriate selected. It is highlighted that unlike the carbides 
embedded in the matrix, which have a globular shape, the carbides placed in the interface area are elongated. As a result of their elongated shape, these carbides are stress concentrators and in combination with their high hardness can cause the layer failure by mechanical stress. The local chemical analyses using EDX technique were performed at the interlayer interface as well as on different constituents. It is highlighted that in the lighter areas the $\mathrm{W}$ is predominant, and in the dark grey areas the concentration of $\mathrm{Cr}$ is higher as well as $\mathrm{C}, \mathrm{Fe}, \mathrm{Ni}$ and $\mathrm{Co}$ are present in the matrix. The aspect of fracture surfaces for the samples prepared by depositing of 4 successive layers by HVOF thermal spraying process of WOKA 7504 powder is presented in Fig. 10. For the sample with the S235JR substrate, although macroscopically no cracks were revealed in the layer, failure occurred at the layer substrate interface, Fig. 10a.

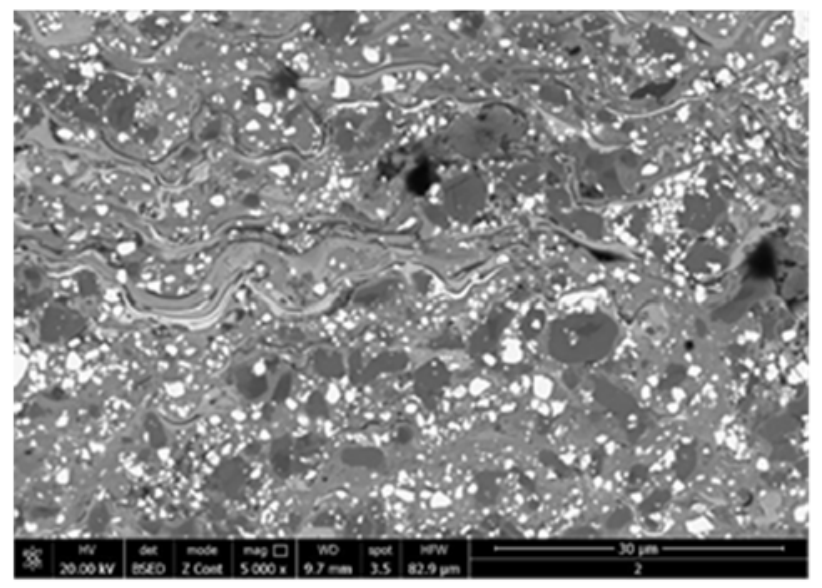

Fig. 9. The SEM microscopic aspect in cross-section of a sample with two deposited layer achieved by HVOF thermal spraying process of WOKA 7504 powder

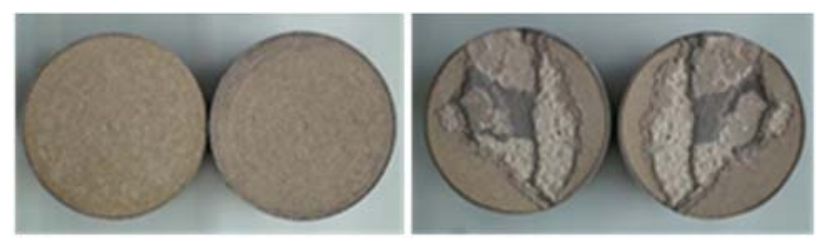

Fig.10. The aspect of samples fracture surfaces, with 4 deposited layers achieved by HVOF thermal spraying process of WOKA 7504

powder, after performing adhesion tests: a) $\varnothing 25 \mathrm{~mm}$ sample,

S235JR substrate; b) $\varnothing 25 \mathrm{~mm}$ sample, 304L substrate

This aspect, together with the average value of adhesion strength of $19.7 \mathrm{~N} / \mathrm{mm}^{2}$ emphasizes that, in this case, the layer adherence to the substrate is relatively low.

A lower adhesion strength of $11.7 \mathrm{~N} / \mathrm{mm}^{2}$ was recorded for the 304L substrate (about two times lower than the adhesion strength obtained in case of two layers), and macroscopically mixed fractures and cracks in the deposited layers were revealed, Fig. 10b. Figure 11 presents the aspects of the fracture surface resulting after the adhesion tests in case of 6 layers' deposition, after performing adhesion tests. In both cases (S235JR substrate, Fig. 11a and 304L substrate, Fig. 11b) the failure surface shows a mixed fracture, at the layer substrate interface and as well as between layers deposited successively.

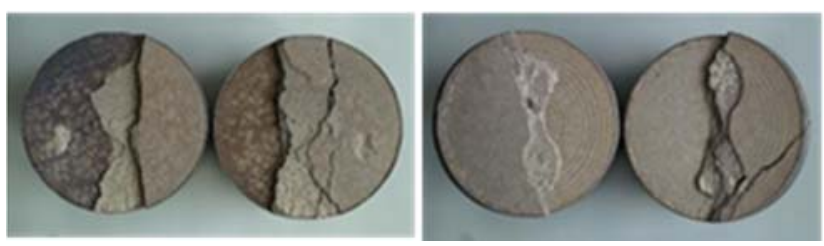

Fig.11. The aspect of samples fracture surfaces, with 6 deposited layers achieved by HVOF thermal spraying process of WOKA 7504

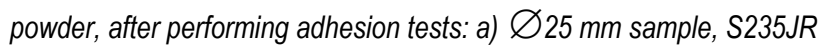

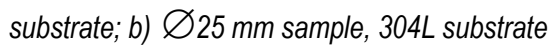

Macroscopically, cracks in the deposited layer and local layer exfoliation were highlighted. These facts, in conjunction with lower average values of the adhesion strength of $16.0 \mathrm{~N} / \mathrm{mm}^{2}$ for S235JR support and only of $8.0 \mathrm{~N} / \mathrm{mm}^{2}$ in the case of $304 \mathrm{~L}$ substrate (about 3 times lower than the adhesion strength obtained by depositing of two layers), show that the layer adhesion to the substrate is particularly low in these cases. Also, in the case of the S235JR substrate, a more intense colouring of the metal substrate can be noticed, that indicates a pronounced heating of the sample during the HVOF thermal spraying process occurred.

Figure 12 and 13 presents the micro structural aspect of a sample with six deposited layer, indicates the propagation direction of interlayer crack and reveals some fine cracks developed perpendicular to it toward the outer surface of the deposition (Fig. 12). The cracks were initiated in the inter layer interface area (Fig. 13) with elongated and hard carbides of $\mathrm{W}$, that failed under thermal stress, and propagated through the matrix.

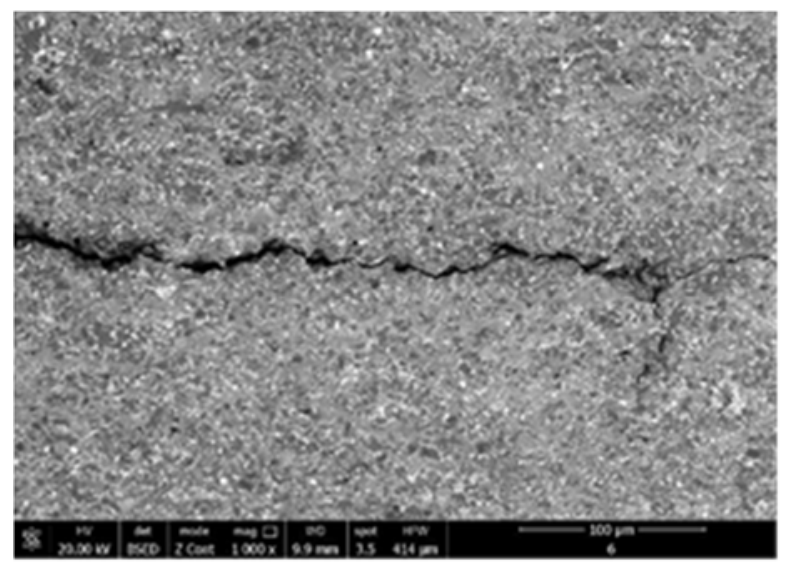

Fig. 12 The SEM microscopic aspect in cross-section of a sample with six deposited layer achieved by HVOF thermal spraying process of WOKA 7504 powder: inter and intralayer crack propagation

The properties of WC-CrC-Ni coatings obtained using optimal technological parameters of the HVOF process were previously investigated by W. Fang and collaborator [41] and by M. M. El Rayes and collaborator [42]. They found that these HVOF coatings are compact and are very protective for the substrate, having good thermal stability, 
good corrosion resistance and excellent wear resistance. On the other hand, they concluded that the chemical composition of the metallic binder and the occurrence of micro cracks were the most important factors influencing the corrosion resistance of the HVOF sprayed WC coatings in the strong acidic environment. The enhanced corrosion resistance of HVOF coatings has been explained by S. M. Hassani-Gangaraj and collaborator [29], due to the presence of $\mathrm{Cr} 2 \mathrm{O} 3$ in protective layers. Thereby, Chromium having very high affinity for oxygen, forms stable oxide and inhibits the substrate oxidation by blocking the diffusion of reacting species. Thus, the HVOF thermal spraying process is recommended to be used in the case where the oxides' formation is the main protective mechanism.

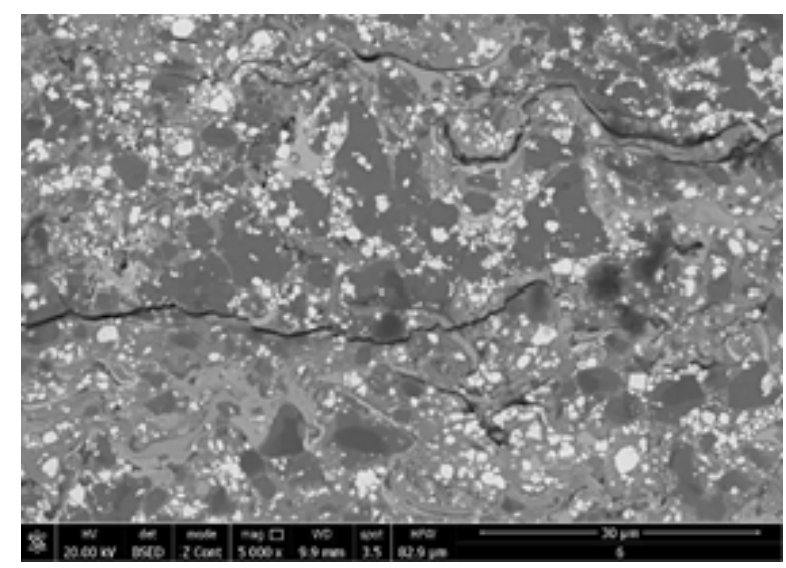

Fig.13. The SEM microscopic aspect in cross-section of a sample with six deposited layer achieved by HVOF thermal spraying process of WOKA 7504 powder: crack in the interlayer interface

The experimental results support these observations, allowing validation of assumptions that in case of $\mathrm{WC}$ $\mathrm{CrCNi}$ hard coatings, obtained by the HVOF thermal spraying process, the deposition thickness plays a decisive role on adhesion strength and on the existence of a critical thickness starting from which the deposition quality is affected. Additionally, it was also revealed that this critical value is closely related to the occurrence of pores and micro-cracks in the coating layers. This issue is linked to the technological parameters of the HVOF thermal spraying process, whereas by variation of the velocity and

temperature of the sprayed particle, the substrate temperature could be modified in order to avoid internal stress in the coating layers and finally to achieve the optimal deposited layer thickness.

Many experimental and analytical efforts have been carried out in order to provide a better understanding of the bonding mechanism in the HVOF thermal spraying process, but currently the accurate bonding mechanism is still a matter of debate. In general, a critical velocity for the spraying particle is needed to produce localisation of those to the substrate interface. As a result of particle impact, a strong pressure is exerted on the substrate and a shear load is generated, which accelerates the material laterally, and thus during high strain rate deformation, strengthening occurs as a result of substrate metal dislocation and contraction of the plasticised sprayed particle. Usually increasing the temperature of the sprayed particle by using a proper oxygen-fuel ratio is good, since plastic deformation of the powders is induced and thus less porous coatings are obtained. On the other hand, in the case of continuous deposition of many layers, our experimental results reveal the fact that too much heat input into substrate is not good from the coating adhesion strength point of view, since the main adhesion mechanism is based on the mechanical anchoring of hot sprayed particles to the surface irregularities of the substrate, which occurs as a result of the sudden contraction of the plasticized particle in contact with the colder substrate, due to temperature differences between them. If the substrate temperature is too high, this effect does not occur and moreover cracks are initiated in or between the coating layers due to the internal stresses induced during cooling as a result of the difference between the thermal expansion coefficients of the substrate and coating materials.

\section{Conclusions}

The paper illustrates the influence of deposition thickness on adhesion strength of $\mathrm{WC}-\mathrm{CrC}-\mathrm{Ni}$ coatings obtained by the HVOF thermal spraying process of WOKA 7504 powder. In this case, the existence of a critical coating thickness, starting from which the adhesion strength, and generally the deposition quality, is affected due to the occurrence of elongated carbides or fine micro crack in the coating layer has been revealed. Best experimental results regarding the adhesion strength have been obtained for two layers deposited with a total thickness of $220 \mu \mathrm{m}$. Once the total thickness of the coating increased to over 400 - $650 \mu \mathrm{m}$, elongated carbides placed in the interlayer interface could fails due to the internal thermal stress induce by the HVOF process and micro crack occurred, which leads to the reduction of the adhesion strength and even causes layer cracking. It has been shown that the adhesion of $\mathrm{WC}-\mathrm{CrC}-\mathrm{Ni}$ thermal sprayed powder on the S235JR structural steel substrate is higher to that achieved for $304 \mathrm{~L}$ austenitic steel substrate, due to a better mechanical anchoring of the plasticized particulate on the structural steel substrate. In this regard, tensile adhesion tests have shown an average adhesion strength of $35.8 \mathrm{~N} / \mathrm{mm}^{2}$ for structural steel substrate and of $23.4 \mathrm{~N} / \mathrm{mm}^{2}$ for stainless steel substrate, used in the experimental work. Whereas the technological parameters are closely related to the adhesion mechanism, by choosing the proper ones related to the heat input and to the substrate temperature, the HVOF process could be controlled in order to obtain high quality coatings. In the industrial applications, in order to reduce the internal thermal stresses due to overheating, and thus to reduce the risk of cracks occurrence in the coating layer of the component subjected to the HVOF thermal spraying process, the parameters of the process have to properly adapt to the shapes and dimensions of components. The 
manufacturing of thick layers over $100 \mu \mathrm{m}$ per pass should be avoided, since it significantly increases the substrate temperature and thus the residual stresses; (e.g. 30-50 $\mu \mathrm{m}$ per pass could be a good choice). The process must be carried out intermittently, so that the component can be able to cool before the deposition of the next layer. Monitoring the temperature of components is recommended to be carried out during and / or after the deposition of each layer.

\section{ACKNOMEDGEMENTS}

This work was supported by the Romanian National Authority for Scientific Research and Innovation ANCSI and was carried out as part of a NUCLEU research program, project no. PN 1608 201. The authors would like to acknowledge the support provided by the National R\&D Institute for Welding and Material Testing - ISIM Timisoara and by the Research Institute for Renewable Energy Timisoara, for all the facilities necessary to implement the experimental research.

\section{REFERENCES}

[1] P. S. Mohanty, Challenges in thermal spraying of refractory materials, Surf. Eng., 2005, 21, p 1-4.

[2] A. C. Karaoglanli, H. Caliskan, M. S. Gok, A. Erdogan and A. Turk, A comparative study of the microabrasion wear behavior of CoNiCrAlY coatings fabricated by APS, HVOF, and CGDS Techniques, Tribol. T., 2014, 57, p 11-17.

[3] R. Giusti, S. Vezzù and G. Lucchetta, Wear-resistant cobalt-based coatings for injection moulds by cold spray, Surf. Eng., 2016, 32, p 677-685.

[4] B. Z. Duan, P. Z. Zhang, X. F. Wei, L. Wang, D. B. Wei and D. D.Zhen ,Effects of elements $W$ and $\mathrm{C}$ on microstructure and wear property of $\gamma$-TiAl surface alloying layer, Surf. Eng., 2015, 31, p 942948.

[5] J. Tian,W. H. Yu,W. Tian,J. Zhao,Y. Q. Li and Y. Z. Liu, Effects of Y-Ce on wear behaviours of silicide coatings, Surf. Eng., 2015, 31, p 289-294.

[6] Y.-G. Li, Y.-H. Wei, L.-F. Hou, C.-L. Guo and P.-J. Han, Wear and electrochemical behaviour of $\mathrm{Mg}-\mathrm{Al}$ intermetallic coating, Surf. Eng., 2014, 30, p 933938.

[7] Tarasi, F., Mahdipoor, M.S., Dolatabadi, Medraj, A. M., Moreau, C., HVOF and HVAF Coatings of Agglomerated Tungsten Carbide- Cobalt Powders for Water Droplet Erosion Application, J. Therm. Spray Tech., 2016, 25, p 1711-1723.

[8] M. Winnicki, A. Baszczuk, M. RutkowskaGorczyca, A. Małachowska and A. Ambroziak, Corrosion resistance of tin coatings deposited by cold spraying, Surf. Eng., 2016, 32, p 691700.

[9] S. B. Mishra and S. Prakash, Erosion-corrosion behaviour of $\mathrm{Ni}-20 \mathrm{Cr}$ plasma coating in actual boiler environment, Surf. Eng., 2015, 31, p 29-38.
[10] H. Q. Yang, Z. J. Yao, D. B. Wei, W. B. Zhou, G. X. Yin and L. X. Feng, Anticorrosion of thermal sprayed Al-Zn-Si coating in simulated marine environments, Surf. Eng., 2014, 30, p 801-805.

[11] M. M. Verdian, Characterisation and corrosion performance of HVOF sprayed Ni-10 wt-\% $\% \mathrm{Ti}$ coatings, Surf. Eng., 2014, 30, p 670-674.

[12] Liu, Y., Hang, Z., Chen, H., Ceng, S., Gou, G., Wang, X., Tu, M. and Wu, X., Erosion-Corrosion Property of CeO2-Modified HVOF WC- Co Coating, J. Therm. Spray Tech., 2016, 25, p 815822.

[13] A. C. Karaoglanli, A. Turk and I. Ozdemir, Effect of sintering on mechanical properties of cold sprayed thermal barrier coatings, Surf. Eng., 2016, 32, p 686-690.

[14] M. Pourbafrani, R. Shoja Razavi, S. R. Bakhshi, M. R. Loghman- Estarki and H. Jamali, Effect of microstructure and phase of nanostructured YSZ thermal barrier coatings on its thermal shock behaviour, Surf. Eng., 2015, 31, p 64-73.

[15] A. C. Karaoglanli, A. Turk, I. Ozdemir, and F. Ustel, Comparison of Oxidation and Thermal Shock Performance of Thermal Barrier Coatings, Mater. Manuf. Process, 2015, 30, p 717-723.

[16] C.R.C. Lima and J.M. Guilemany, Adhesion improvements of thermal barrier coatings with HVOF thermally sprayed bond coats, Surf. Coat. Tech., 2007, 201, p 4694-4701.

[17] L. Pawlowski, The Science and Engineering of Thermal Spray Coatings, 2nd edn, 85-89; 2008, Chichester, John Wiley \& Sons, Ltd. [18] H. Singh, T. S. Sidhu and S. S. Kalsi, Microstructure study of cold sprayed $50 \% \mathrm{Ni}-50 \% \mathrm{Cr}$ coating on Inconel601, Surf. Eng., 2015, 31, p 825-831.

[19] S. Hong, Y. P. Wu, W. W. Gao, B. Wang, W. M. Guo, and J.R. Lin, Microstructural characterisation and microhardness distribution of HVOF sprayed WC-10Co-4Cr coating, Surf. Eng., 2014, 30, p 5358.

[20] L. M. Berger, S. Saaro, T. Naumann, M. Kasparova and F. Zahalka, Microstructure and Properties of HVOF-Sprayed WC-(W,Cr)2C-Ni Coatings, $J$. Therm. Spray Techn., 2008, 17, p 395-403.

[21] P. Cavaliere and A. Silvello, Fatigue behaviour of cold sprayed metals and alloys: critical review, Surf. Eng., 2016, 32, p 631-640.

[22] J. G. La Barbera-Sosa, Y. Y. Santana, J. Caro, D. Chicot, J. Lesage, M. H. Staia and E. S. PuchiCabrera, Mechanical properties of WC coatings evaluated using instrumented indentation technique, Surf. Eng, 2014, 30, p 498-510.

[23] S. Nourouzi, M. Jalali Azizpour and H. R. Salimijazi, Parametric Study of Residual Stresses in HVOF Thermally Sprayed WC-12Co Coatings, Mater. Manuf. Processes, 2014, 29, p 1117-1125.

[24] Z. H. Masuku, P. A. Olubambi, J. H. Potgieter and B. A. Obadele, Tribological and Corrosion Behavior of HVOF-Sprayed WC-Co- Based Composite 
Coatings in Simulated Mine Water Environments, Tribol. T., 2015, 58, p 337-348.

[25] Wesmann, J.A.R., Kuroda, S. and Espallargas, N. J, The Role of Oxide Tribofilms on Friction and Wear of Different Thermally Sprayed WC- CoCr, $J$. Therm. Spray Tech., 2017, doi:10.1007/s11666-0170522-0.

[26] H. Masoumi, S. M. Safavi, M. Salehi and S. M. Nahvi, Effect of Grinding on the Residual Stress and Adhesion Strength of HVOF Thermally Sprayed WC-10Co-4Cr Coating, Mater. Manuf. Processes, 2014, 29, p 1139-1151.

[27] T. Yang, M. Yu, H. Chen, W. Y. Li and H. L. Liao, Characterisation of cold sprayed Al5056/SiCp coating: effect of SiC particle size, Surf. Eng., 2016, 32, p 641-649.

[28] M. Kumarasamy and S. Natarajan, Selection and characterisation of HVOF cermet coatings for volutes of high capacity pumps of opencast lignite mines, Surf. Eng., 2016, 32, p 229-237.

[29] S. M. Hassani-Gangaraj, A. Moridi and M. Guagliano, Critical review of corrosion protection by cold spray coatings, Surf. Eng., 2015, 31, p 803815.

[30] M. Oksa, E. Turunen, T. Suhonen, T. Varis and S.-P. Hannula, Optimization and Characterization of High Velocity Oxy-fuel Sprayed Coatings: Techniques, Materials, and Applications, Coatings, 2011, 1, p 17-52.

[31] M. Taheri, Z. Valefi, K. Zangeneh-Madar, Influence of HVOF process parameters on microstructure and bond strength of NiCrAlY coatings, Surf. Eng., 2012, 28, p 226-272.

[32] Song, B., Bai, M., Voisey, K.T. and Hussain, T., Role of Oxides and Porosity on High-Temperature Oxidation of Liquid-Fueled HVOF ThermalSprayed Ni50Cr Coatings, J. Therm. Spray Tech., 2017, doi:10.1007/s11666-017-0531-z.

[33] C. J. Huang and W. Y. Li, Strengthening mechanism and metal/ceramic bonding interface of cold sprayed TiNp/A15356 deposits, Surf. Eng., 2016, 32, p 663-669.
[34] M. J. Azizpour, H. M. Majd, M. Jalali and H. Fasihi, AdhesionStrength Evaluation Methods in Thermally Sprayed Coatings, Int. J. Mech. Aeros. Ind. Mechatronic Manuf. Eng., 2012, 6, p 337-339.

[35] M. Hadad, G. Marot, Ph. Démarécaux, J. Lesage, J. Michler and S. Siegmann, Adhesion tests for thermal spray coatings: Application range of tensile, shear and interfacial indentation methods, Proc. Conf. ITSC 2005 on 'Thermal Spray connects: Explore its surfacing potential!', Basel, Switzerland, May 2005, DVS, p 759-764.

[36] M. Arrigoni, S. Barradas, M. Braccini, M. Dupeux, M. Jeandin, M. Boustie, C. Bolis and L. Berthe, A comparative study of three adhesion tests (EN 582, similar to ASTM C633, LASAT (LASer Adhesion Test), and bulge and blister test) performed on plasma sprayed copper deposited on aluminium 2017 substrates, J. Adhesion Sci. Technol., 2006, 20, p 471-487.

[37] Thermal spraying. Determination of tensile adhesive strength, EN 582:1993.

[38] Standard Specification for Stainless Steel Bars and Shapes, ASTM A276M-16a.

[39] Hot rolled products of structural steels, Part 2, Technical delivery conditions for non-alloy structural steels, EN 10025-2:2004.

[40] Material Product Data Sheet. Chromium Carbide 37\% Tungsten Carbide - 18\% Metal Alloy, 2014, Oerlikon Metco, available at [www.oerlikon.com/ecomaXL/files/oerlikon_DSMT S-0056.3_Woka7500_C2C3_37WC_18Alloy.pdf], (accessed [Nov.2016])

[41] W. Fang, T.Y. Cho, J. H. Yoon, K.O. Song, S.K. Hur, S.J. Youn and H.G. Chun, Processing optimization, surface properties and wear behavior of HVOF spraying WC-CrC-Ni coating, J. Mater. Process. Tech., 2009, 209, p 3561-3567.

[42] M. M. El Rayes, H. S. Abdo and K. A. Khalil, Erosion Corrosion of Cermet Coating, Int. J. Electrochem. Sci., 2013, 8, p 1117-1137 